\title{
Pohjaveden korkeuden vaikutus happaman sulfaattimaan dityppioksidiemissioihin lysimetrikokeessa
}

\author{
Asko Simojoki ${ }^{1)}$, Seija Virtanen ${ }^{1)}$ ja Markku Yli-Halla ${ }^{1)}$ \\ Elintarvike- ja ympäristötieteiden laitos, PL 27, 00014 Helsingin yliopisto, \\ asko.simojoki@helsinki.fi, seija.virtanen@helsinki.fi, markku.yli-halla@helsinki.fi
}

\section{Tiivistelmä}

Viljelyksessä olevien happamien sulfaattimaiden (HS-maat) valumavedet heikentävät alapuolisten vesistöjen laatua Itämeren rannikolla, koska näiden maiden sisältämät sulfidit muodostavat hapettuessaan rikkihappoa. Sulfidit sijaitsevat pääosin HS-maiden syvemmissä kerroksissa, salaojitetulla maalla tyypillisesti syvemmällä kuin $1 \mathrm{~m}$ (C-horisontti). Nämä kerrokset sisältävät suuria määriä hiiltä ja typpeä, ja niiden mikrobiologinen aktiivisuus on potentiaalisesti suuri. HSmaiden C-horisonttien hapettuminen ei näin ollen ainoastaan tuota rikkihappoa, vaan voi myös lisätä maan mikrobiologista aktiivisuutta ja johtaa hiili- ja typpivarastojen osittaiseen mobilisoitumiseen. Säätöojitus ja pohjaveden nosto ovat mahdollisia keinoja, joilla voidaan vähentää HS-maiden hapettumista ja hapon muodostusta. Korkea pohjavesi voi kuitenkin samalla lisätä denitrifikaatiota ja dityppioksidin $\left(\mathrm{N}_{2} \mathrm{O}\right)$ emissioita maaperästä ilmakehään.

Tämän CATERMASS LIFE+ -hankkeeseen kuuluvan seurannan tavoitteena oli selvittää, lisääkö pohjaveden nostaminen $\mathrm{N}_{2} \mathrm{O}$-emissiota HS-maasta (Sulfic Cryaquept). Emissiomittauksia tehtiin suljetun kammion menetelmällä kasvukaudella 2010 lysimetrikokeessa, jossa pohjavesi pidettiin joko korkealla (20 cm syvyydessä) tai matalalla $(65 \mathrm{~cm})$. Kokeessa oli mukana sekä ruokohelpeä kasvavia että kasvittomia lysimetrejä. Emissioita mitattiin kahden viikon välein, tai päivittäin kahden kolme päivää kestäneen simuloidun rankkasadejakson aikana. Samanaikaisesti pintamaan huokosvedestä otettiin näytteitä, joista analysoitiin liuennut typpi ja hiili.

Liuenneen typen pitoisuus ja $\mathrm{N}_{2} \mathrm{O}$-emissiot olivat suurimmillaan välittömästi typpilannoituksen jälkeen keväällä, minkä jälkeen kasvien ravinteenotto nopeasti vähensi sekä liuennutta typpeä että emissioita. Dityppioksidin emissiot olivat yleensä samaa suuruusluokkaa riippumatta siitä, oliko pohjavesi säädetty korkealle vai matalalle. Tämän tutkimuksen tulokset eivät tue käsitystä, että HSmaiden pohjaveden nosto lisäisi merkittävästi maaperän $\mathrm{N}_{2} \mathrm{O}$-emissioita.

Asiasanat: Happamat sulfaattimaat, denitrifikaatio, dityppioksidi, kasvihuonekaasuemissiot, korkea pohjavesi, liukoinen typpi, mikrobiaktiivisuus, ruokohelpi 


\section{Johdanto}

Suomessa arvioidaan olevan maatalouskäytössä 67 000-130 000 ha happamia sulfaattimaita, pääosin Pohjanlahden rannikolla (Yli-Halla ym. 1999). Ne sisältävät runsaasti muinaisen Litorina-meren aikana syntyneitä sulfidirikkaita sedimenttejä. Viljelyksessä olevien happamien sulfaattimaiden (HSmaat) valumavedet heikentävät alapuolisten vesistöjen laatua Itämeren rannikolla, koska sulfidit muodostavat hapettuessaan rikkihappoa (Roos ja Åström 2006). Sulfidit sijaitsevat pääosin HSmaiden syvemmissä kerroksissa, salaojitetulla maalla tyypillisesti syvemmällä kuin $1 \mathrm{~m}$ (Chorisontti). Nämä kerrokset sisältävät suuria määriä hiiltä ja typpeä, ja niiden mikrobiologinen aktiivisuus on potentiaalisesti suuri (Simek ym. 2011). HS-maiden C-horisonttien hapettuminen ei näin ollen ainoastaan tuota rikkihappoa, vaan voi myös lisätä maan mikrobiologista aktiivisuutta ja johtaa hiili- ja typpivarastojen osittaiseen mobilisoitumiseen. Säätöojitus ja pohjaveden nosto ovat mahdollisia keinoja, joilla voidaan vähentää HS-maiden hapettumista ja hapon muodostusta. Korkea pohjavesi voi kuitenkin samalla lisätä denitrifikaatiota ja dityppioksidin $\left(\mathrm{N}_{2} \mathrm{O}\right)$ emissioita maaperästä ilmakehään eri mekanismeilla (MacDonald ym. 2010). Tämän CATERMASS LIFE+ -hankkeeseen (Suomen ympäristökeskus 2011) kuuluvan seurannan tavoitteena oli selvittää, lisääkö pohjaveden nostaminen $\mathrm{N}_{2} \mathrm{O}$-emissiota happamasta sulfaattimaasta.

\section{Aineisto ja menetelmät}

Happaman sulfaattimaan dityppioksidiemissioiden seuranta osana CATERMASS LIFE+ -hanketta (Suomen ympäristökeskus 2011) toteutettiin kasvukaudella 2010 lysimetrikokeessa, jossa tutkittiin 2008-2010 pohjaveden korkeuden vaikutusta ruokohelven kasvuun sekä maan kemiallisiin muutoksiin ja valumavesien happamuuteen (Virtanen ym. 2010). Kahdeksassa lysimetrissä kasvatettiin ruokohelpeä, ja kaksi lysimetriä olivat kasvittomia. Lysimetrit olivat 200 litran PVC-putkia, joiden pohjalla oli $80 \mathrm{~cm}: n$ kerros happaman sulfaattimaan hapettuneita (B-horisontti) ja pelkistyneitä (Chorisontti) pohjamaakerroksia sisältävä luonnollinen maamonoliitti, ja tämän päällä $20 \mathrm{~cm}: n$ kerros eihapanta muokkauskerroksen maata. Hapan sulfaattimaa oli peräisin Helsingin yliopiston Viikin koetilan Patoniityn peltolohkolta $\left(60^{\circ} 13^{\prime} \mathrm{N}, 25^{\circ} 0^{\prime} \mathrm{E}\right)$, jonka maa on liejusavea ja jonka maannos amerikkalaisen luokituksen (Soil Taxonomy) mukaan on Sulphic Cryaquept (Mokma ym. 2000, YliHalla ym. 2000, 2008), ja ei-hapan maa Viikin koetilan Taka-Hakalan peltolohkolta, jonka muokkauskerros on runsasmultaista hietamoreenia.

Koe järjestettiin Helsingin yliopiston Viikin kampuksella lasikattoisessa ja verkkoseinäisessä kasvihuoneosastossa. Lysimetreihin oli rakennettu pohjaveden korkeuden säätösysteemi sekä asennettu antureita redox-potentiaalin, vesipitoisuuden, lämpötilan ja huokosveden koostumuksen mittaamiseksi maan eri syvyyksiltä. Koekäsittelyt olivat:

- HWC korkea pohjavesi (20 cm syvyys), kasvillinen

- LWC matala pohjavesi (65 cm syvyys), kasvillinen

- HWB korkea pohjavesi (20 cm syvyys), kasviton

Pohjaveden pinta säädettiin tavoitetasoon kasvukauden alussa. Kaikkiin lysimetreihin lisättiin ruokohelven normaaleja lannoitesuosituksia vastaavat määrät lannoiteliuosta maan pinnalle noin viikon kuluttua pohjaveden pinnan säädöstä (N 90, P 5 ja K 40 kg / ha). Kaikkia lysimetrejä kasteltiin keinosadevedellä muutaman päivän välein paikallisen sadannan pitkäaikaisen keskiarvon mukaisesti.

Kaasuemissioita mitattiin suljetun kammion menetelmällä kahden viikon välein toukokuun alusta lokakuun puoleen väliin, ja päivittäin kahden kolme päivää kestäneen, simuloidun rankkasadejakson aikana. Emissiokammiona käytettiin kuhunkin lysimetriin pysyvästi asennettua teräslieriötä (läpimitta $16 \mathrm{~cm}$, kokonaiskorkeus $25 \mathrm{~cm}$, maanpäällisen osan korkeus $15 \mathrm{~cm}$ ), joka suljettiin mittauksen ajaksi neopreenikalvolla ja josta otettiin 7 ml:n kaasunäytteitä butyylikumiseptumeilla suljettuihin, vakumoituihin lasiampulleihin ( $3 \mathrm{ml}$ Exetainer $\left.{ }^{\circledR}\right)$ 1, 20, 40 ja 60 min kannen sulkemisen jälkeen. Kaasunäytteiden koostumus määritettiin kaasukromatografilla (Jaakkola ja Simojoki 1998). Emissiomittausten yhteydessä otettiin myös pintamaasta $10 \mathrm{~cm}: \mathrm{n}$ syvyydestä huokosvesinäytteet, joista määritettiin liuenneen typen ja hiilen kokonaispitoisuudet (Shimadzu TOC- $\mathrm{V}_{\mathrm{CPH} / \mathrm{CPN}}$ total organic carbon analyzer). 


\section{Tulokset ja niiden tarkastelu}

Huokosveteen liuenneen typen pitoisuus ja $\mathrm{N}_{2} \mathrm{O}$-emissio olivat kaikissa koejäsenissä suurimmillaan toukokuun alussa välittömästi typpilannoituksen jälkeen. Kasvillisessa maassa ne pienenivät tämän jälkeen nopeasti, ja pysyivät matalalla tasolla koko seurantajakson ajan (Kuva 1). Sitä vastoin kasvittomassa maassa liuenneen typen pitoisuus oli välittömästi lannoituksen jälkeen korkeampi kuin kasvillisessa maassa. Kasvittomassa maassa liuenneen typen pitoisuus ja $\mathrm{N}_{2} \mathrm{O}$-emissio pienenivät hitaammin kuin kasvillisessa maassa.
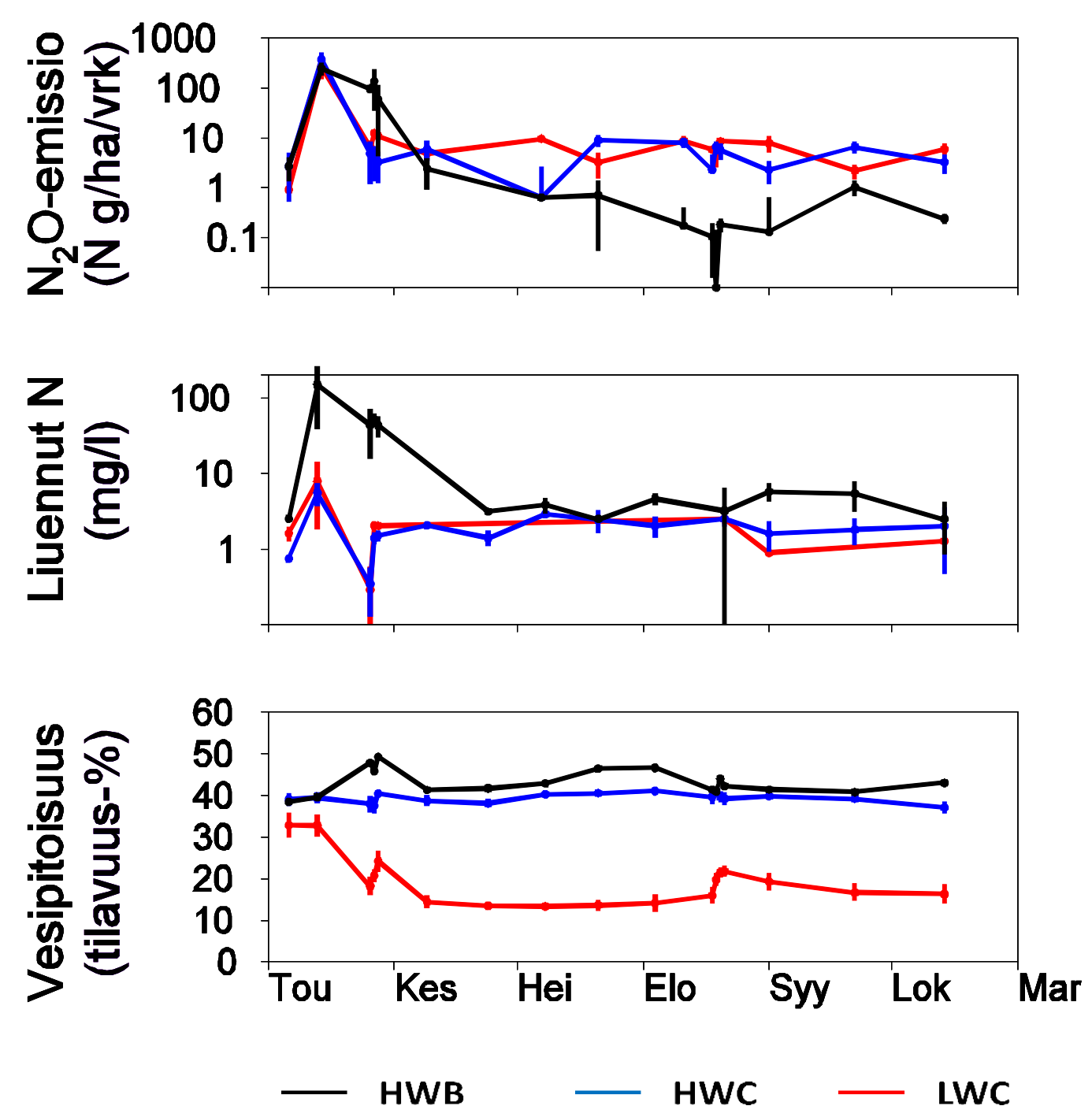

Kuva 1. Dityppioksidiemissio, liuenneen typen pitoisuus ja maan vesipitoisuus eri koekäsittelyissä (keskiarvo \pm keskihajonta, $\mathrm{n}=2-4$ ).

Koejäsenissä, joissa pohjavettä pidettiin $20 \mathrm{~cm}$ syvyydellä, pintamaan vesipitoisuus $15 \mathrm{~cm}: n$ syvyydellä oli koko seurantajakson ajan noin 40 til-\%, kasvittomassa maassa jopa hieman korkeampi. Koska pintamaan kokonaishuokoisuus oli kasvillisissa koejäsenissä noin 55 til- \%, ja kasvittomissa 50 til-\%, maassa oli ilmatilaa korkeintaan 10-15 til-\% ja huokosten vedenkyllästysaste oli yli $70 \%$. Tämän tulkitaan yleisesti tarkoittavan, että maan ilmavuus on todennäköisesti ainakin ajoittain riittämätön: juuret kärsivät hapenpuutteesta, ja denitrifikaatiota esiintyy, jos maassa on runsaasti nitraattia. Tämän mukaisesti suuria $\mathrm{N}_{2} \mathrm{O}$-emissioita havaittiin heti lannoituksen jälkeen. Tässä kokeessa hapenpuute ei kuitenkaan rajoittanut ruokohelven kasvua, vaikka pohjavettä pidettiin korkealla, vaan pohjaveden nosto lisäsi ruokohelven kasvua, todennäköisesti edistämällä kasvin vedensaantia (Epie ym. 2012).

Koejäsenissä, joissa pohjavettä pidettiin matalalla $(65 \mathrm{~cm})$, pintamaan vesipitoisuus kasvukauden aikana oli yleensä vain noin 15 til-\% (40 \% ilmaa) ja huokosten vedenkyllästysaste alle $30 \%$. Tällaisessa maassa kasvit eivät kärsi merkittävästi hapenpuutteesta ja denitrifikaatio on vähäistä. Suurimpien $\mathrm{N}_{2} \mathrm{O}$-emissioiden aikaan välittömästi lannoituksen jälkeen vesipitoisuus oli kuitenkin matalan pohjaveden käsittelyssäkin vielä yli 30 til-\% (veden kyllästysaste noin $60 \%$ ), jolloin denitrifikaatiota saattoi tapahtua huomattavassa määrin.

Seurantajakson alkupuolella havaitut suuret $\mathrm{N}_{2} \mathrm{O}$-emissiot johtuivat epäilemättä lannoitetypen denitrifioitumisesta. Typpilannoituksen aiheuttamat $\mathrm{N}_{2} \mathrm{O}$-emissiopiikit ovat yleisiä kaikissa 
maalajeissa, kun nitraatin vähäisyys rajoittaa denitrifikaatiota. Tässä kokeessa kasvien tehokas ravinteenotto ilmeisesti vähensi nopeasti sekä liuennutta typpeä että emissioita kasvillisessa maassa. Vertailu kasvittomaan maahan osoittaa, että kasvillisissa lysimetreissä liuennut typpi väheni lähinnä kasvin ravinteenoton ennemmin kuin denitrifikaation seurauksena, sillä kasvittomassa maassa typpipitoisuudet pysyivät pitempään korkeina ja $\mathrm{N}_{2} \mathrm{O}$-emissiot pienenivät hitaammin kuin kasvillisessa maassa. Kasvillisissa lysimetreissä dityppioksidin emissiot olivat yleensä samaa suuruusluokkaa riippumatta siitä, oliko pohjavesi säädetty korkealle vai matalalle. Kokonaisemissio 161 vrk kestoisen seurantajakson aikana oli kaikissa koejäsenissä noin 4,0 $\pm 0,7 \mathrm{~kg}(\mathrm{~N}) / \mathrm{ha}$.

\section{Johtopäätökset}

Typpilannoitus aiheuttaa happamista sulfaattimaista suuria $\mathrm{N}_{2} \mathrm{O}$-päästöjä välittömästi lannoituksen jälkeen samaan tapaan kuin muista maista. Kasvien ravinteenotto vähentää tehokkaasti huokosveteen liuennutta typpeä ja $\mathrm{N}_{2} \mathrm{O}$ :n päästöjä maaperästä ilmakehään. Kumulatiiviset $\mathrm{N}_{2} \mathrm{O}$ päästöt olivat melko suuria, mutta korkea pohjavesi ei lisännyt kokonaispäästöjä seurantajakson aikana. Tämän tutkimuksen tulokset eivät tue käsitystä, että HS-maiden pohjaveden nosto lisäisi merkittävästi $\mathrm{N}_{2} \mathrm{O}$-päästöjä maaperästä ilmakehään.

\section{Kirjallisuus}

Etone E.K., Virtanen S., Simojoki A. \& Stoddard, F. 2012. High moisture acid sulphate soil effects on reed canary grass. Maataloustieteen Päivät 2012.

Jaakkola, A. \& Simojoki, A. 1998. Effect of soil air composition and nitrous oxide emission in a loam soil. Agricultural and Food Science in Finland 7: 491-505.

Macdonald B., White I. \& Denmead T. 2010. Gas emissions from the interaction of iron, sulfur and nitrogen cycles in acid sulfate soils. Congress Symposium 4. 19th World Congress of Soil Science, Soil Solutions for a Changing World. 1 - 6 August 2010, Brisbane, Australia. Julkaistu DVD:nä.

Mokma, D.L., Yli-Halla, M. \& Hartikainen, H. 2000. Soils in a young landscape on the coast of southern Finland. Agricultural and Food Science in Finland 9:291-302.

Roos, M. \& Åström, M. 2006. Gulf of Bothnia receives high concentrations of potentially toxic metals from acid sulphate soils. Boreal Environment Research 11: 383-388.

Simek, M., Virtanen, S., Kristufek, V., Simojoki, A. \& Yli-Halla, M. 2011. Evidence of rich microbial communities in the subsoil of a boreal acid sulphate soil conducive to greenhouse gas emissions, Agriculture, Ecosystems and Environment 140:113-122.

Suomen ympäristökeskus 2011. Happamien sulfaattimaiden ympäristöriskien vähentäminen sopeutumiskeinoja ilmastomuutokseen (CATERMASS). Verkkosivu: http://www.ymparisto.fi/syke/catermass (viitattu 5.12.2011).

Virtanen S., Simojoki A. \& Yli-Halla M. 2010. Monolithic lysimeters as tools to study the composition of pore and drainage waters responding to high water table in boreal acid sulphate soil. Working Group 3.1. 19th World Congress of Soil Science, Soil Solutions for a Changing World. 1 - 6 August 2010, Brisbane, Australia. Julkaistu DVD:nä.

Yli-Halla, M., Puustinen, M. \& Koskiaho, J. 1999. Area of cultivated acid sulfate soils in Finland. Soil Use and Management 15:62-67.

Yli-Halla, M., Mokma, D.L., Peltovuori, T. \& Sippola, J. 2000. Suomalaisia maaprofiileja. Maatalouden tutkimuskeskuksen julkaisuja. Sarja A 78. $32 \mathrm{~s}$.

Yli-Halla M., Mokma D.L, Wilding L.P. \& Drees L.R. 2008. Morphology, Genesis and Classification of Acid Sulphate Soils of Finland. Teoksessa: Proceedings of the Joint Conference of the $6^{\text {th }}$ International Acid Sulfate Soil Conference and the Acid Rock Drainage Symposium, (toim.) C. Lin, S. Huang, Y. Li, s. 224-228. Guangdong Press Group: Guangzhou. 